healthy pas; strength of patient improving, and the general symptoms favourable. To-day I made an incision into a small collection of matter on the posterior surface of the shoulder, from which I extracted four shot.

May 8th.--The patient is now walking about, and the old wound healing steadily. I lave had a couple of gum splints constructed, which envelop the side of the chest, the shoulder, and arm down to below the elbow. By the aid of this shield, I am enabled to keep the fractured bone in a quiet, steady position, and am yet led to hope, that, by proper care, a pretty firm union of the bone may still be attained. The general health and strength of the patient are almost restored. Diet and general treatment, such as is calculated to promote the strength of the patient.

12th. - To-day the patient was embarked on board the steam frigate Auckland, for passage to Bombay. His strength is so far restored, that he was able, without fatigue, to walk some little distance to the beach. The arm retained in the gum splints.

22nd.-Last evening, the patient arrived safely at Bombay, from Bassadore. The wound all cicatrized to about the size of a shilling at its centre, and this healthy and closing in rapidly. The fracture is pretty firmly adherent, though it can scarcely be considered ossific as yet. There is much reason to hope, however. that the latter object will be yet attained. Health and strength quite re-established. The patient has been sent on shore to day to the Naval Sanatarium, under the charge of Assistant-Surgeon Reynolds, the port surgeon.

Aug. 8th.-A few days after the last report, I was hurriedly dispatched from Bombay to Aden, so that in the mean time I was debarred from ohserving the progress of my patient. Today, however, he arrived here upon his passage to England, and $I$ had an opportunity of examining him. He is in robust health. The gun-shot wound has quite healed over, and the union of the fracture has become perfectly firm and ossific. He has full power over the motions of the hand, forearm, and elbow-joint. The movements of the shoulder, as was to be expected, are of course yet feelle; but it is beyond all doubt, that ere the expiration of six months, he will have a very excellent arm. It is a matter of surprise to me, too, that notwithstanding the excision of the portions of humerus, and the present overlapping of the fragments, there is, upon the most careful measurement, only a shortening of the arm to the amount of an inch and a half.

Fra. 3.

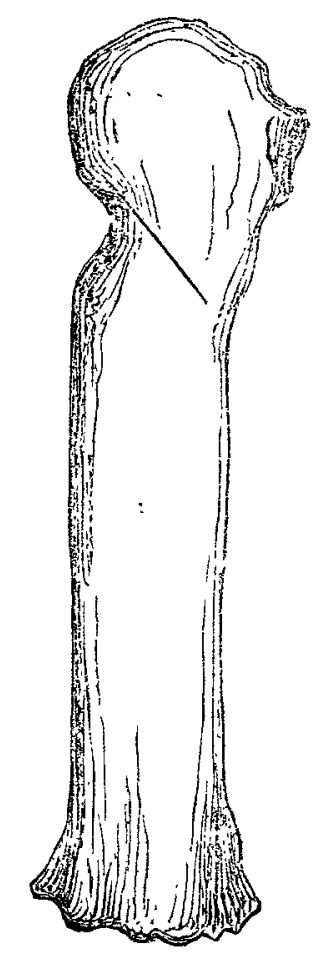

Fig. 3 is intended to convey my idea of how the bone has united, and what its present shape may be supposed to resemble.

(To be concluded in our next.)

New Medical College.-The Subscriptions now amount to nearly $£ 3000$.
CLINICAL REMARKS ON A CASE OF

ASTHMATIC BREATHING, OCCASIONED BY AN ANEURISM OF THE THORACIC AORTA.

By C. J. B. ALDIS, M.D.

$\mathrm{J}_{\mathrm{OHN}} \mathrm{J}-$, aged forty-five, residing at Pimlico, came under my care at the St. Paul and Barnabas Dispensary, on the 30th of August last.

I always visited him at home in consequence of the severe embarrassment in his breathing. He was rather tall and well-proportioned, the chest being fully developed. The first symptom which struck me on entering his room was a very loud tracheal râle during inspiration; his countenance, hands, and body were remarbably exsanguine, the hands almost white. He seemed to be afraid of the least exertion, lest the dyspnoea should be increased. The pulse feeble and regular; very little cough; no expectoration; in fact, there was no expectoration until towards the termination of the complaint. The chest was resonant on percussion, and no bruit could be detected over the cardiac region. The very loud sonorous inspiration, however, was sufficient to mask any slight murmur which might have existed. He stated that at the commencement of his illness he had lost his voice, which had since returned. There was no impulsive action of the heart. Previous to this attack, he had lived with Lady $\mathrm{D}-$ as groom of the chamber, and before that at Wimbledon, where he slept in a damp room, to which he attributed his illness.

On first seeing this patient, one might naturally ask, was the dyspnoea entirely spasmodic? But the attacks were not sufficiently transient. Again, was it the extension of laryngitis to the mucous membrane of the trachea, causing permanent thickening? But there had been no cough at the commencement, and no expectoration. Did it arise from pulmonary disease? but the lungs were resonaut, indeed more resonant than natural, which might have led any one to suppose that they were somewhat emphysematons. "The cause evidently existed close to the trachea, for on applying the stethoscope in the front part of the neck the loudest râle was heard just below the larynx. From these circumstances it was supposed that a tumour of some kind pressed upon the trachea, causing mechanical obstruction to the respiration. On one occasion when I visited him, Sept. 27 th, a loud sonorous râle accompanied each inspiration, followed by a loud cooing sound during expiration. There was no orthopnoea, and the illness was said to have commenced about three months ago. He had been an outpatieut at St. George's Hospital for about a fortnight before I saw him, but only went there three times, and was obliged to go in a cab.

The treatment consisted of counter-irritation with sedatives, stimulants, inhalation, and mild aperients. The difficulty of breathing becoming worse, he sank very gradually, and died on the 29 th of September.

A post-mortem examination of the body took place on the 30 th of $B$ eptember, when the following appearances were detected:-Body remarkably pale; there was a deposit of fat under the shin, and the muscles were well coloured, contrasting very much with the external paleness. On opening the thorax, the lungs collapsed but little; there was no emphy. sema, and they were healthy, but contained more than the usual quantity of air; no effusion into the chest; the heart healthy as to its dimensions and valves, but somewhat flabby; the vessels contained much fluid blood, with a long yellowish coagulum in the aorta, containing dark-coloured blood. On detaching the vessels from the heart, a tumour was observed in the arch of the aorta pressing on the trachea, which was taken out with it, including the larynx. On passing the finger into the aorta, it entered the swelling, which proved to be an aneurismal pouch. These appearances satisfactorily explained the previous symptoms. Had the patient survived much longer, the probability is, that the aneurism would have burst into the trachea, and suffocated him. Sometimes it enlarges very much, causing absorption of the vertebræ and ribs, and a tumour is formed external to the chest, which has been mistaken for an abscess, showing the necessity of making a very careful examination before plunging a lancet into some swellings. Occasionally the aorta is merely dilated without any well-formed pouch. In this morbid specimen you observe a distinct arterial sac, which pathologists term an aneurism. The coats are all entire, in which case it is called atria aneurism. Occasionally the two inner coats give way, leaving the outer coat, which is called a false aneurism. Should another pouch be formed out of the external coat, it is said to be "mixed." If the blood pass between the internal and middle coats through an aperture, obliterating a part of the channel, 
and re-enter the artery beyond the part so obliterated, causing an extended swelling, it is designated diffused aneurism. The symptoms of this disease are liable to be marked by the wheezing of bronchitis if complicated with it, especially if the circulation be very languid, as in this case, the heart not having the power of propelling the blood with any degree of vigour into the minute vessels. We know that sometimes murmurs appear, and they disappear according to the state of the circulation and vigour of the heart, ever in extensive ossification of the cardiac valves. The patient presented the appearance usually called in females, "chlorotic;" but the post-mortem examination showed, from the good colour of the muscles, that there was much more blood in the body than, à priori, we should have expected.

\section{ON A CASE OF BUTTON SCURVY.}

By J. W. EDMONDS, Esq., Camberwell.

A воUт the 13th of September, 1851, T. G- applied to me with a circumscribed, strawberry-looking swelling on the palm of the hand, about the size of a small walnut. He was a stont, well-built, active young man. Being not quite clear as to the nature of the disease, I directed him to apply to St. Thomas's Hospital.

On the 20th of September he again applied to me, with the hand and arm greatly swollen, and the tumour looking inclined to increase in every direction. A small spot appeared on the back of the hand, which seemed to threaten a second edition of what was going on in the palm of the hand. Having observed an account of the button scurvy, and my patient being a milkman, his cows being in the same field where sheep were pastured, I determiner this as a case of button scurvy; and considering the irritation so great that the more powerful caustics were inarmissible, I applied lead lotion to the hand and arm, supporting them with a sling, and touched the whole of the surface of the tumour with tincture of the sesqui-chloride of iron twice daily. The hand, arm, and tumour steadily improved until the 2 nd of October, when he worked with the haud, and inflammation was set up, and matter poured out underneath the tumour, which was now only dead skin. He had a linseed-meal poultice over the whole of the front and back of the hand, the partially dead surface of the tumour being dressed with mercurial ointment and white precipitate. On the fourth of October a little pus was discharged from the tumour, and all bad symptoms subsided. He continued the dressing until the $10 \mathrm{ch}$ of October, when the hand appeared well. I have seen him this day, and consider him cured.

Camberwell, Oct. 23, 1851 .

\section{Jforeign 速epartment.}

Unsuccessful Transfusion of Blood in a Case of Ancemia.

M. Monneret has recently communicated the following case to the Academy of Medicine of Paris:-A woman, twenty-eight years of age, was admitted into the "Flopital Beaujon" on the 4 th of October, 1851, with severe symptoms of anæmia and scurvy. The patient had from childhood been subject to frequent bomorrhage, but the loss of blood was now confined to the uterus and the formation of petechiæ. There was a certain amount of obesity, the mucous membrane was everywhere extremely pale, and various parts of the body were covered with ecchymoses. The weakness was extreme, the viscera appeared healthy, there was complete anorexia, constipation, and tympanitis.

The debility increased rapidly, notwithstanding the liberal administration of tonics and stimulants, and on the second day after admission the patient was dying. M. Monneret, looking at the alteration of the blood as of a primary character, and independent of any visceral disease, resolved to try transfusion. Four ounces of blood, deprived of fibrine, or, in other words, the serosity and globules with the elements which are held in solution in the former, were contintuously injected with hardly an interruption of two minutes. Some excitement and improvement were produced for a short time; the patient took some wine with pleasure; but these favourable symptoms did not last long; she gradually became weaker, and died the same night in the manner of consumptive patients. The autopsy revealed no alterations but such as are cominon to anæmia; nor did the blood, before or after death, present any change as to the fibrine or globules. The author thinks that the patient died in consequence of the tupefaction produced by the transfusion, and strongly condemns the operation, though it had been devised by himself. The blood had been defibrinated to prevent the bad effects which coagulation of the injected fluid might produce.

\section{A New Remedy for Intermittent Fever.}

It will be recollected that a plant, called cedron, was lately brought back from South America, as very efficacious against rabies. Herein, however, it has been found powerless. But M. Lewr, who has just returned from South America, has brought with him, among other curiosities, some of the root of the cedron, which, though unsuccessful in rabies, has been found particularly serviceable in ague, in the dose of between seven and fifteen grains per diem.

\section{Trephining for Caries of Bone.}

M. JULES RoUx, chief surgeon of the naval department at Toulon, has published, in $L^{\prime}$ Union Médicale, a few eases which would tend to show that among the various means usually employed to arrest caries of bone, trephining should not be neglected. He had employed the trephine at the base of the petrous bone, which had been carious for several years. When a circular piece of bone had been removed, a deep cavity was laid bare, in which the index finger came in contact with the meninges. The case did well, and good results were also obtained in a second, where trephining was used upon the canine fossa of the superior maxilla, after the soft parts had been dissected and thrown upwards. Trephining is pretty frequently used in this country for facilitating the removal of necrosed portions of bone, but seldom for mere caries.

\section{Rheumatic Inflammation followed by Suppuration.}

M. Becquener has recently brought the following case before the Medical Society of the Hospitals of Paris. An attendant at the hospital of "La Pitié," forty-five years of age, who had never been seriously ill, was suddenly seized with febrile symptoms, and two or three days afterwards swelling and pain attacked the ankle-joint on the right side. He was given twenty-two grains of quinine, and this dose was repeated the next day. On the second day after the seizure the pain and swelling had much diminished, but on the third and fourth day, the right knee swelled and became very painful. The quinine was now continued for two days, but as no improvement was noticed, the patient was bled, and leeches were applied to the knee. Mercurial frictions were subsequently had recourse to, but with no abatement of the symptoms; the man became, on the contrary, much weaker, and died fourteen days after the onset of the disease.

No general inspection was made, but the articulations which had been attacked were examined. The ankle, which had suffered first, was perfectly sound, but the knee had undergone severe pathological changes: the ligaments were partially destroyed, the synovial sac was full of pus, and this fluid had burrowed as far as the superior third of the thigh. These purulent collections might have filled a tumbler.$M$. Becquerel thought this case of importance, as the patient had never suffered from any previous affection, and because there existed no abscess about the frame which might suggest the idea that the pus had been absorbed and deposited in the knee. We must, however, observe that there is no certainty on this head, as the whole body was not examined.

\section{Thebiefos and Notices of Bbooks.}

The Spine: its Curvatures and other Diseases; their Symptoms, Treatment, and Cure; to which are anded some Remarks on Paralysis. By Charles Verral, M.R.C.S., Surgeon to the Hospital for the Cure of Distortions, Portland-road, and the Sea-Bathing Infirmary at Eastbourne, Fellow of the Medical Society of London, and late House-Surgeon to the Asylum for the Treatment of Spinal Deformities. 8vo. London, 1851.

Previoushy to entering into an examination of the volume before us, it may not be uninteresting to many of our readers,now that the treatment of the affections of the spinal column and of deformities generally has become recognised as a part of legitimate medicine and surgery, and honourable for men of science to pursue,-to briefly trace the history of the insti- 